\title{
Efeito de Aditivos no Valor Nutritivo de Silagens feitas com Subproduto da Extração do Palmito de Pupunha (Bactris gasipaes H.B.K.) ${ }^{1}$
}

\section{Antonio José Rodrigues Neto², Antonio Fernando Bergamaschine ${ }^{3}$, Olair José Isepon ${ }^{3}$, João Batista Alves ${ }^{3}$, Fernando Braz Tangerino Hernandez ${ }^{4}$, Marcelo Pereira Macedo ${ }^{5}$}

\begin{abstract}
RESUMO - O objetivo deste experimento foi determinar a qualidade e o valor nutritivo de silagens do subproduto da pupunha, produzidas com aditivos, conforme os tratamentos: $\mathrm{T}_{1}$ - Testemunha (sem aditivo); $\mathrm{T}_{2}$ - Adição de 2,5\% de açúcar; $\mathrm{T}_{3}$ - Adição de $10,0 \%$ de polpa cítrica e $\mathrm{T}_{4}$ - Adição de 10,0\% de milho moído, base da matéria natural. Verificou-se que a adição 10\% de polpa cítrica (PC) ou milho moído (MM) elevou o teor de matéria seca da massa a ser ensilada, bem como da silagem, em 6,5 e 8,0 unidades percentuais, respectivamente. Silagens com aditivos apresentaram menores valores de nitrogênio amoniacal $\left(\mathrm{N}_{-} \mathrm{NH}_{3} / \mathrm{NT}\right)$ e pH. O consumo de matéria seca foi maior para as silagens feitas com PC ou MM, atingindo $85 \mathrm{~g} / \mathrm{kg} \mathrm{PV}^{0,75}$ ou 2,1\% do PV, contra $44,7 \mathrm{~g} / \mathrm{kgPV}^{0,75} \mathrm{ou} 1,12 \%$, para as silagens sem aditivo ou com $2,5 \%$ de açúcar. O coeficiente de digestibilidade aparente da matéria seca, também foi superior para as silagens contendo $10 \%$ de PC ou MM $(65,0 \%)$ em relação à média das demais (52,0\%). A digestibilidade da parede celular não mostrou tendência definida em função dos tratamentos. A silagem de subproduto da pupunha feita com a adição de $10 \%$ de polpa cítrica ou milho moído, apresentou valor nutritivo semelhante às silagens de forrageiras convencionais.
\end{abstract}

Palavras-chave: consumo, digestibilidade, polpa cítrica

\section{Effect of Additives on Nutritive Value of Silages Based on Palm Cabbage Production By-products from Pupunha (Bactris gasipaes)}

\begin{abstract}
The objective of this experiment was to evaluated the effect of additives on the quality and nutritive value of silages made with pejibaye palm by-product, according to the following treatments: $\mathrm{T}_{1}$ - Control (without additive); $\mathrm{T}_{2}-\mathrm{Addition}_{\mathrm{i}}$ of $2.5 \%$ of sugar; $\mathrm{T}_{3}$ - Addition of $10.0 \%$ of citric pulp and $\mathrm{T}_{4}$ - Addition of $10.0 \%$ of ground corn, based on natural matter. The use of $10.0 \%$ of citric pulp (CP) or ground corn (GC) increased dry matter content of the by-product prior to ensilage and of the silage by 6,5 and 8,0 percentage units, respectively. The use of additives resulted in smaller values of ammoniacal nitrogen $\left(\mathrm{N}-\mathrm{NH}_{3} / \mathrm{TN}\right)$ and $\mathrm{pH}$. Dry matter intake was higher for silage made with $\mathrm{CP}$ or GC, mean value of $85.0 \mathrm{~g} / \mathrm{kgLW}^{0.75}$ or $2.1 \%$ of $\mathrm{LW}$, compared to the others $\left(44.7 \mathrm{~g} / \mathrm{kgLW}^{0.75}\right.$ or $1.12 \%$ of $\left.\mathrm{LW}\right)$. Also, apparent dry matter digestilibity coefficient was higher for silage containing $10 \% \mathrm{CP}$ or GC $(65.0 \%)$ in comparison to the others $(52.0 \%)$. Cell wall digestibility did not show a defined trend as a function of the treatments. Silage made of by-product pejibaye with $10.0 \%$ of citrus pulp or ground corn showed a nutritional value similar to conventional forage silages.
\end{abstract}

Key Words: citric pulp, intake, digestibility

\section{Introdução}

O uso de subprodutos da produção de palmitos pode ser uma alternativa a mais para suplementar o gado na época de escassez de pasto.

A pupunha é uma palmeira perene, nativa das regiões tropicais da América Latina, como a região Amazônica, onde os seus frutos são utilizados como alimento para o homem e na fabricação de farinha para uso na alimentação humana e animal (TONET et al., 1999a). No entanto, o esgotamento das reservas naturais de palmito e a necessidade de preserva- ção dos ecossistemas florestais têm possibilitado a expansão da cultura da pupunha nas regiões Sudeste e Centro-Oeste, visando à produção de palmito. De acordo com TONET et al. (1999a), o Brasil é o maior produtor, exportador e consumidor de palmito do mundo, atingindo um consumo de $100 \mathrm{mil}$ t/ano, baseado principalmente na extração de palmáceas nativas.

Levantamento realizado entre setembro de 1997 e março de 1998 (TONET et al., 1999b) indicou, com algumas ressalvas, que no Estado de São Paulo podem estar implantados 1824 ha da cultura de pupunha, que corresponde a 9,12 milhões de pés.

\footnotetext{
${ }^{1}$ Parte da Dissertação de Mestrado do primeiro autor.

2 Engenheiro-Agrônomo, CATI. E.mail: catiandra@andranet.com.br

3 Prof. do Depto. de Zootecnia - UNESP/FE, Cx. P. 31, Ilha Solteira/SP. E.mail: berga@bio.feis.unesp.br

4 Prof. do Depto de Ciência do Solo e Eng. Rural - UNESP/FE. E.mail:fbthtang@agr.feis.unesp.br

5 Aluno de Mestrado em Zootecnia. UNESP/FE, Cx. Postal, 31, Ilha Solteira/SP.
} 
Após a extração do palmito, sobram as folhas, bainhas e parte dos caules, que podem ser utilizados na alimentação de ruminantes. As poucas informações existentes indicam que se trata de um subproduto com elevado potencial para este uso.

Em culturas adubadas e irrigadas, o primeiro corte da pupunha ocorre entre 18 e 24 meses. Subsequientemente os perfilhos oferecem cortes a cada 3-4 meses, atingindo até $100 \mathrm{t} / \mathrm{ha} / \mathrm{ano}$ de material residual (ALVES JR. et al., 1999) com a seguinte composição química: matéria seca, 26,0\%; proteína bruta, $8,3 \%$; cinzas, $7,9 \%$; extrato etéreo, $5,5 \%$; fibra detergente neutro, $56,4 \%$ e fibra detergente ácido, $37,2 \%$. Estes valores diferem daqueles obtidos por MEDEIROS (1999), PB, 10,0\%; FDN, 62,0\%; FDA, 50,0\%; celulose, 30,0\%; e lignina, $15,0 \%$, ou da fração folhas analisada por ANDRADE (1997); MS, 34\%; PB, 7,5\%; FDN, 65,0\%.

Quanto ao desempenho animal, MEDEIROS (1999) observou que bovinos cruzados, com $392 \mathrm{~kg}$ e 36 meses, recebendo 1,5; 3,0 e 4,5 kg/dia de concentrado e subproduto da extração de palmito pupunha, in natura picado, ganharam 0,796; 0,920 e 0,858 kg/ dia, respectivamente.

Dessa forma, o potencial forrageiro da pupunha, expresso em termos de produção de matéria seca, teores de PB e FDN, quando comparado com aqueles obtidos com híbridos de milho (ALMEIDA FILHO et al., 1999), híbridos de sorgo (CANDIDO et al., 1999), capim-elefante (BOTREL e XAVIER, 1998) e canade-açúcar (MAZZA, 1993), fica bastante próximo, tanto em produção como em qualidade. Isto demonstra que os subprodutos da pupunha oferecem potencial para uso in natura, logo após a extração do palmito, ou preservado na forma de silagem.

No entanto, a produção de silagem a partir do subproduto de pupunha exigirá algumas tecnologias apropriadas. De acordo com Wilkinson et al. (1982), citados por VILELA (1998), na ensilagem de plantas que apresentam teores de matéria seca inferiores a $21 \%$, carboidratos solúveis inferiores a $2,2 \%$ na matéria verde e baixa relação entre carboidratos e poder tampão, os riscos de fermentação secundária são maiores. Nesta situação, o uso de aditivos é fundamental para melhorar a fermentação no silo.

$\mathrm{O}$ uso de aditivos secos na ensilagem, como fontes de carboidratos solúveis e redutores de umidade, entre eles o melaço de cana, milho moído e polpa cítrica, foi amplamente discutido por LAVEZZO (1993), LAVEZZO e ANDRADE (1994), VILELA (1998).

$\mathrm{A}$ adição de 3,0 a 5,0\% (matéria natural) de melaço, segundo LAVEZZO e ANDRADE (1994), propicia fermentações mais adequadas, melhora o consumo e a digestibilidade da silagem de capimelefante. Os mesmos autores também constataram, pela literatura, que o uso de fubá de milho como aditivo, na ensilagem de capim-elefante, é recomendável, pois, além de elevar o teor de matéria seca, favorecendo a fermentação, eleva o valor energético da silagem. É importante considerar que o amido do milho não é fermentado pelas bactérias láticas (LAVEZZO e ANDRADE, 1994; VILELA, 1998), ao contrário do que ocorre com o açúcar fornecido pelo melaço.

CARVALHO (1994) citou que um subproduto com excelentes características como aditivo é a polpa cítrica seca, pois, além de apresentar alta capacidade de absorção de água ( $145 \%$ do seu peso), apresenta também alto teor de carboidratos solúveis (26,0\% na matéria seca), melhorando fermentação da silagem de capim-elefante e o seu valor nutritivo (FARIA et al., 1972). O nível de adição de polpa cítrica na forragem varia de 10 a $20 \%$ na matéria original, conforme revisão de CARVALHO (1994). Baseado em dados de campo, esse autor afirma que a inclusão de $20 \%$ de polpa cítrica ao capim-elefante possibilita a confecção de silagens de qualidade e custo semelhantes à silagem de milho.

O presente trabalho teve como objetivo avaliar o efeito do açúcar, polpa cítrica e milho moído sobre o valor nutricional de silagens do subproduto da pupunha.

\section{Material e Métodos}

O experimento foi conduzido na Fazenda de Ensino e Pesquisa da Faculdade de Engenharia de Ilha Solteira - UNESP, Estado de São Paulo, no período de fevereiro a julho de 1998.

O subproduto da pupunha (caule, folhas e bainhas) foi cedido pela Fazenda Nossa Senhora Aparecida, localizada no Município de Santa Mercedes, na região Oeste Paulista. Nesta propriedade, a cultura da pupunha é adubada e irrigada e a colheita foi realizada aos 24 meses do plantio.

O subproduto foi picado 12 horas após sua obtenção em quantidade proporcional (caule, folha e bainha) e alternada, em picadeira JF-90 acoplada ao trator e coletado em uma carreta onde era misturado. O tamanho das partículas do material picado era bem variável. O caule e a bainha resultavam em forragem com partículas menores $(0,5-1,0 \mathrm{~cm})$ e finas, enquanto as folhas geravam material mais comprido, 
retalhado e sem tamanho definido, porém o pecíolo era reduzido a partículas inferiores a $1,0 \mathrm{~cm}$.

A forragem foi ensilada em silos do tipo poço, de alvenaria, com capacidade para 1,2 t. Foram confeccionadas quatro tipos de silagens, constituindo os seguintes tratamentos: $\mathrm{T}_{1}$ - Testemunha (sem aditivo); $\mathrm{T}_{2}$ - Adição de 2,5\% de açúcar; $\mathrm{T}_{3}$ - Adição de $10,0 \%$ de polpa cítrica e $\mathrm{T}_{4}$ - Adição de $10,0 \%$ de fubá, na base da matéria natural. A polpa peletizada passou por uma moagem grosseira, com fragmentação de $80,0 \%$ dos peletes. O açúcar cristal foi utilizado em substituição ao melaço de cana, não disponível na ocasião.

A compactação foi realizada pelo pisoteio constante de duas pessoas. Durante o enchimento dos silos, foram retiradas cinco amostras de cada um, em duplicata. Cinco amostras foram destinadas à análise de carboidratos solúveis pelo método de JOHNSON et al. (1966) e as restantes secas em estufa de circulação de ar forçada regulada a $55-60^{\circ} \mathrm{C}$ e, posteriormente, moídas para passagem em peneira de $1 \mathrm{~mm}$. Nestas foi determinado o poder tampão (PT), segundo PLAYNE e McDONALD (1966), além de matéria seca (MS), proteína bruta $(\mathrm{PB})$, fibra bruta (FB), extrato etéreo (EE), matéria mineral (MM) e componentes da parede celular, de acordo com SILVA (1981). As análises de Ca, P, $\mathrm{Mg}$, $\mathrm{S}$ e K seguiram as metodologias descritas por MALAVOLTA et al. (1997).

Aproximadamente 60 dias após o enchimento, os silos foram abertos. Amostras em duplicada foram retiradas a cada três dias; da metade delas foi retirado o suco, através de prensa hidráulica para leitura direta do $\mathrm{pH}$ e determinação do nitrogênio amoniacal pelo método modificado por TOSI (1973). Nas restantes foram realizadas análises bromatológicas de rotina, inclusive dos componentes da parede celular (SILVA, 1981).

Além de avaliar os parâmetros relacionados com a composição bromatológica e aqueles inerentes ao processo fermentativo, foi conduzido um ensaio com bovinos para determinação do consumo e digestibilidade in vivo.

O experimento de consumo e digestibilidade teve duração de 25 dias, sendo 15 em baias individuais, para adaptação às silagens e avaliação do consumo nos últimos quatro dias. Foram utilizados 16 bezerros da raça Guzerá com pesos próximos de $180 \mathrm{~kg}$. As silagens experimentais foram oferecidas duas vezes ao dia (8 e 16 horas), em quantidades que permitiam sobras de aproximadamente $10 \%$ do oferecido, para controle do consumo. O período de coleta em gaiolas metabólicas foi de sete dias, precedidos de três dias de adpatação. Nesse período, o consumo foi restrito a $90 \%$ do consumo voluntário individual. O único suplemento para as silagens foi $30 \mathrm{~g} / \mathrm{cab} / \mathrm{dia}$ de sal mineralizado.

A coleta de fezes foi realizada duas vezes a cada 24 horas ( 16 h e 8 h). Alíquotas de $5 \%$ da produção diária foram congeladas a $-10^{\circ} \mathrm{C}$. Após o período de coleta, formaram-se amostras compostas por animal. Eventuais sobras de silagem foram pesadas, amostradas e compostas por animal. Amostras de fezes e sobras foram secas em estufa de circulação de ar forçada regulada a $55-60^{\circ} \mathrm{C}$, moídas a $1 \mathrm{~mm}$ e submetidas às mesmas análises das silagens.

Os teores de nutrientes das forragens e das silagens, bem como os valores de consumo, dos coeficientes de digestibilidade dos nutrientes e valores de nutrientes digestíveis totais das silagens, foram analisados segundo um delineamento inteiramente casualizado com quatro repetições. As médias foram comparadas pelo teste Tukey, a 5\% de probabilidade.

\section{Resultados e Discussão}

Observa-se na Tabela 1 que a adição de $10 \%$ de polpa cítrica (PC) ou milho moído (MM) elevou $(\mathrm{P}<0,05)$ o teor de matéria seca em relação ao tratamento sem aditivo (Testemunha), em 8 unidades percentuais. A adição de açúcar (A), em nível de $2,5 \%$, não alterou significativamente o teor de matéria seca da forragem. O valor de $28,0 \%$ de $\mathrm{MS}$, atingido pela adição de $10 \%$ de aditivo (PC ou MM), coincide com o valor mínimo (28,0\%) preconizado por McDONALD et al. (1988), para forragens úmidas submetidas ao pré-murchamento.

Os tratamentos não afetaram os teores de proteína da forragem, cuja média foi de $10,2 \%$, sendo em média $62,0 \%$ superior aos observados por ALMEIDA FILHO et al. (1999) para forragens de híbridos de milho.

$\mathrm{A}$ adição de $\mathrm{A}$ ou $\mathrm{MM}$ provocou queda $(\mathrm{P}<0,05)$ no poder tampão (PT). O mesmo não ocorreu com a presença de PC, possivelmente devido ao seu alto teor de cálcio. Trabalhando com ensilagem de capimelefante, ANDRADE et al. (1998) observaram queda no PT, quando a matéria seca foi elevada para próximo de $30 \%$, pela adição de $6 \%$ de rolão de milho. $\mathrm{O}$ valor de 28,2 e.mg HCl/100 g MS obtido para o subproduto sem aditivo (T) é igual ao encontrado por TOSI et al. (1983) e ANDRADE e LAVEZZO 
(1998a) para o capim-elefante também sem aditivo. TOSI et al. (1983) consideraram este valor elevado.

O teor de carboidratos solúveis (CHOS) aumentou $(\mathrm{P}<0,05)$ com o uso de $2,5 \%$ de A. Acréscimo maior foi observado por TOSI et al. (1995) com a adição de $4 \%$ de melaço ao capim-elefante. Surpreendentemente, tanto a PC como o MM não elevaram $(\mathrm{P}>0,05)$ o teor de $\mathrm{CHOS}$, no subproduto da pupunha pré-ensilagem, ao contrário de FARIA et al. (1972), trabalhado com níveis de 10\% de PC adicionada ao capim-elefante, e VAN ONSELEN e LOPES (1988), também com capim-elefante, e níveis de $9,0 \%$ de fubá. Falta de efeito sobre o teor de CHOS foi notada por ANDRADE et al. (1998) e ANDRADE e LAVEZZO (1998a), adicionando rolão de milho ao capim-elefante pré ensilagem. Estes autores observaram, ao contrário, ligeira queda, provavelmente pelo efeito diluição. Segundo
LAVEZZO (1993), o milho como fonte de CHOS não apresenta efeito consistente. No presente ensaio, o teor de CHOS em todos os tratamentos situou-se entre 12 a $16 \%$ na matéria seca, valores recomendados para gramíneas tropicais (LAVEZZO e ANDRADE, 1994).

O baixo teor de fibra de todos os aditivos testados resultou em queda $(\mathrm{P}<0,05)$ nos componentes da parede celular da massa a ser ensilada, fato também observado por RUGGIERI (1996) no preparo da ensilagem de alfafa com milho moído. Entretanto, a adição de rolão de milho na ensilagem de capimelefante, resultou em pequena elevação no teor de fibra detergente neutro (ANDRADE et al., 1998).

Quanto aos teores de minerais, observa-se que a PC proporcionou elevação $(\mathrm{P}<0,05)$ no teor de cálcio. Esse resultado está relacionado ao elevado teor desse mineral na PC, que, segundo CARVALHO (1994),

Tabela 1 - Composição química (\% MS) de amostras do subproduto da pupunha, retiradas no momento da ensilagem, em função dos tratamentos

Table 1 - Chemical composition (\% DM) of palm by-product prior to ensilage, according to treatments

\begin{tabular}{|c|c|c|c|c|c|}
\hline \multirow[t]{2}{*}{$\begin{array}{l}\text { Parâmetros } \\
\text { Parameter }\end{array}$} & \multicolumn{4}{|c|}{$\begin{array}{c}\text { Tratamentos } \\
\text { Treatments } \\
\end{array}$} & \multirow[b]{2}{*}{$\mathrm{CV} \%$} \\
\hline & $\begin{array}{l}\mathrm{T} \\
C \\
\end{array}$ & $\begin{array}{c}\mathrm{A}(2,5 \%) \\
S \\
\end{array}$ & $\begin{array}{c}\mathrm{PC}(10 \%) \\
C P\end{array}$ & $\begin{array}{c}\mathrm{MM}(10 \%) \\
G C\end{array}$ & \\
\hline $\begin{array}{l}\text { MS (\%) } \\
D M\end{array}$ & $20,1^{\mathrm{b}}$ & $22,8^{\mathrm{ab}}$ & $27,9^{\mathrm{a}}$ & $28,2^{\mathrm{a}}$ & 12,9 \\
\hline $\begin{array}{l}\mathrm{PB} \\
C P\end{array}$ & $10,7^{\mathrm{a}}$ & $8,6^{\mathrm{a}}$ & $10,7^{\mathrm{a}}$ & $10,8^{\mathrm{a}}$ & 12,3 \\
\hline $\begin{array}{l}\mathrm{PT}^{1} \\
B C\end{array}$ & $28,2^{\mathrm{b}}$ & $22,1^{\mathrm{c}}$ & $32,2^{\mathrm{a}}$ & $23,6^{\mathrm{c}}$ & 7,6 \\
\hline $\begin{array}{l}\mathrm{CHOS} \\
\mathrm{SCHO}\end{array}$ & $14,1^{\mathrm{b}}$ & $23,6^{\mathrm{a}}$ & $15,8^{\mathrm{b}}$ & $12,2^{\mathrm{b}}$ & 21,0 \\
\hline $\begin{array}{l}\text { FDN } \\
N D F\end{array}$ & $61,9^{\mathrm{a}}$ & $51,6^{\mathrm{c}}$ & $51,7^{\mathrm{c}}$ & $56,1^{\mathrm{b}}$ & 3,8 \\
\hline $\begin{array}{l}\text { FDA } \\
A D F\end{array}$ & $50,2^{\mathrm{a}}$ & $38,4^{\mathrm{c}}$ & $41,6^{\mathrm{b}}$ & $36,2^{c}$ & 4,1 \\
\hline $\begin{array}{l}\text { Celulose } \\
\text { Cellulose }\end{array}$ & $32,9^{\mathrm{a}}$ & $24,8^{\mathrm{c}}$ & $26,5^{\mathrm{b}}$ & $23,0^{\mathrm{d}}$ & 3,2 \\
\hline $\begin{array}{l}\text { Lignina } \\
\text { Lignin }\end{array}$ & $15,6^{\mathrm{a}}$ & $11,9^{b c}$ & $13,0^{\mathrm{b}}$ & $11,5^{\mathrm{c}}$ & 6,4 \\
\hline $\mathrm{Ca}$ & $0,44^{\mathrm{b}}$ & $0,44^{\mathrm{b}}$ & $0,95^{\mathrm{a}}$ & $0,47^{\mathrm{b}}$ & 0,11 \\
\hline $\begin{array}{l}\text { Fósforo } \\
\text { Phosphorus }\end{array}$ & $0,28^{a b}$ & $0,24^{\mathrm{c}}$ & $0,25^{\mathrm{bc}}$ & $0,30^{\mathrm{a}}$ & 5,0 \\
\hline $\begin{array}{l}\text { Magnésio } \\
\text { Magnesium }\end{array}$ & $0,38^{\mathrm{a}}$ & $0,28^{\mathrm{a}}$ & $0,33^{\mathrm{a}}$ & $0,30^{\mathrm{a}}$ & 18,9 \\
\hline $\begin{array}{l}\text { Enxofre } \\
\text { Sulphur }\end{array}$ & $0,13^{\mathrm{ab}}$ & $0,20^{\mathrm{a}}$ & $0,11^{\mathrm{b}}$ & $0,15^{\mathrm{ab}}$ & 22,2 \\
\hline $\begin{array}{l}\text { Potássio } \\
\text { Potassium }\end{array}$ & $1,22^{\mathrm{a}}$ & $1,14^{\mathrm{a}}$ & $1,04^{\mathrm{a}}$ & $1,08^{\mathrm{a}}$ & 0,11 \\
\hline
\end{tabular}

T - testemunha; A - açúcar; PC - polpa cítrica; MM - milho moído; 1 - emg HCl/100g MS; CV - coeficiente de variação.

Médias seguidas de letras distintas, na mesma linha, diferem $(P<0,05)$ pelo teste Tukey.

$C$ - control; $S$ - sugar; $C P$ - citric pulp; GC - ground corn; ${ }^{1} \mathrm{mgeClH} / 100 \mathrm{~g} D \mathrm{M} ; \mathrm{CV}$ - coefficient of variation.

Means followed by different letters, in the same row, are different $(P<.05)$ by Tukey test. 
Rev. bras. zootec.

pode atingir 7,0\%. O efeito dos aditivos sobre os teores de fósforo e enxofre não foi bem definido e não existiu com relação ao magnésio e potássio.

Comparando-se a concentração de minerais do subproduto da pupunha e dados da literatura (BOIN, 1992), observa-se que o teor de $\mathrm{Ca}(0,44 \%)$ foi inferior aos teores de Ca do capim-elefante $(0,82 \%)$ e feno de alfafa $(1,25 \%)$, mas superior ao da silagem de milho $(0,30 \%)$ e do capim-colonião $(0,42 \%)$. Já os teores de P $(0,28 \%)$ e $\mathrm{Mg}(0,38 \%)$ e os de $\mathrm{K}(1,22 \%)$ e S $(0,13 \%)$ estão, respectivamente, acima e abaixo dos citados por BOIN (1992) para os volumosos mais comuns.

Os parâmetros que definem o processo fermentativo das silagens como matéria seca (MS), nitrogênio amoniacal $\left(\mathrm{N}-\mathrm{NH}_{3}\right)$ e $\mathrm{pH}$, além dos teores de proteína bruta $(\mathrm{PB})$, fibra bruta $(\mathrm{FB})$, extrato etéreo (EE), matéria mineral (MM), carboidratos totais (CHOT), bem como os componentes da parede celular (FDN, FDA, celulose e lignina), estão contidos na Tabela 2. A presença da PC e MM elevou
$(\mathrm{P}<0,05)$ o teor de matéria seca das silagens para $26,4 \%$ em média. Este valor está acima do mínimo $25,0 \%$ sugerido por VILELA (1984) para capim, mas ainda está abaixo do mínimo de $28,0 \%$ preconizado por McDONALD et al. (1988). O teor de matéria seca com adição de $\mathrm{A}$ não foi alterado $(\mathrm{P}>0,05) \mathrm{em}$ relação à silagem produzida sem aditivo; a média entre elas foi de $18,3 \%$. Entretanto, enquanto a silagem sem aditivo apresentou fermentação butírica, caracterizada pelos altos teores de $\mathrm{N}-\mathrm{NH}_{3}$ e alto $\mathrm{pH}$, a presença de $2,5 \%$ A reduziu $(\mathrm{P}<0,05)$ estes parâmetros, indicando, provavelmente, a ocorrência de fermentação lática.

Os menores $(\mathrm{P}<0,05)$ valores de $\mathrm{N}-\mathrm{NH}_{3}$ e $\mathrm{pH}$ foram obtidos com o uso de $10 \%$ de $\mathrm{PC}$, enquanto a adição de $10 \%$ de MM foi semelhante àquele com $2,5 \%$ de $\mathrm{A}$, mesmo que a adição do MM tenha proporcionado teor de matéria seca semelhante ao tratamento com PC. Uma possível explicação para esse resultado é que o amido do MM, pouco contribuiu

Tabela 2 - Composição química (\% MS) das silagens de subproduto da pupunha, em função dos tratamentos

Table 2 - Chemical composition (\% DM) of palm by-product silages, according to treatments

\begin{tabular}{|c|c|c|c|c|c|}
\hline \multirow[t]{2}{*}{$\begin{array}{l}\text { Parâmetros } \\
\text { Parameter }\end{array}$} & \multicolumn{4}{|c|}{$\begin{array}{c}\text { Tratamentos } \\
\text { Treatments }\end{array}$} & \multirow[b]{2}{*}{$\mathrm{CV} \%$} \\
\hline & $\begin{array}{l}\mathrm{T} \\
C\end{array}$ & $\begin{array}{c}\mathrm{A}(2,5 \%) \\
S\end{array}$ & $\begin{array}{c}\mathrm{PC}(10 \%) \\
C P\end{array}$ & $\begin{array}{c}\mathrm{MM}(10 \%) \\
G C\end{array}$ & \\
\hline $\begin{array}{l}\mathrm{MS} \\
D M\end{array}$ & $18,1^{b}$ & $18,6^{\mathrm{b}}$ & $25,8^{\mathrm{a}}$ & $27,1^{\mathrm{a}}$ & 7,6 \\
\hline $\begin{array}{l}\mathrm{PB} \\
C P\end{array}$ & $8,5^{\mathrm{c}}$ & $8,5^{\mathrm{c}}$ & $9,6^{\mathrm{b}}$ & $11,2^{\mathrm{a}}$ & 9,7 \\
\hline $\begin{array}{l}\mathrm{N}-\mathrm{NH}_{3} / \mathrm{N} \mathrm{T}^{1} \\
\mathrm{NH}_{3}-\mathrm{N} / T N\end{array}$ & $37,3^{\mathrm{a}}$ & $23,2^{\mathrm{b}}$ & $15,4^{\mathrm{c}}$ & $25,6^{\mathrm{b}}$ & 18,6 \\
\hline $\begin{array}{l}\mathrm{pH} \\
\mathrm{pH}\end{array}$ & $4,4^{\mathrm{a}}$ & $4,0 \mathrm{c}$ & $3,9^{c}$ & $4,2^{\mathrm{b}}$ & 3,2 \\
\hline $\begin{array}{l}\mathrm{FB} \\
C P\end{array}$ & $55,3^{\mathrm{a}}$ & $55,2 \mathrm{a}$ & $39,7^{\mathrm{b}}$ & $33,2^{\mathrm{c}}$ & 7,0 \\
\hline $\begin{array}{l}\mathrm{EE} \\
E E\end{array}$ & $1,7^{b}$ & $3,2^{\mathrm{a}}$ & $2,3^{\mathrm{b}}$ & $3,1^{\mathrm{a}}$ & 22,5 \\
\hline $\begin{array}{l}\mathrm{MM} \\
M M\end{array}$ & $7,5^{\mathrm{a}}$ & $7,2^{\mathrm{a}}$ & $7,0^{\mathrm{a}}$ & $5,4^{\mathrm{b}}$ & 9,3 \\
\hline $\begin{array}{l}\text { CHOT } \\
\text { TCHO }\end{array}$ & $82,3^{\mathrm{a}}$ & $81,0 a^{b}$ & $81,1 \mathrm{a}^{\mathrm{b}}$ & $80,3^{\mathrm{b}}$ & 1,0 \\
\hline $\begin{array}{l}\text { FDN } \\
N D F\end{array}$ & $75,2^{\mathrm{a}}$ & $73,4^{\mathrm{a}}$ & $56,7 \mathrm{c}$ & $60,5^{\mathrm{b}}$ & 3,6 \\
\hline $\begin{array}{l}\text { FDA } \\
A D F\end{array}$ & $61,0^{\mathrm{a}}$ & $60,2^{\mathrm{a}}$ & $49,7^{\mathrm{b}}$ & $39,3^{\mathrm{c}}$ & 3,6 \\
\hline $\begin{array}{l}\text { Celulose } \\
\text { Cellulose }\end{array}$ & $38,3^{\mathrm{a}}$ & $37,3^{\mathrm{a}}$ & $30,5^{\mathrm{b}}$ & $23,7^{\mathrm{c}}$ & 4,6 \\
\hline $\begin{array}{l}\text { Lignina } \\
\text { Lignin }\end{array}$ & $19,4^{\mathrm{a}}$ & $20,0^{\mathrm{a}}$ & $16,9^{b}$ & $14,0 \mathrm{c}$ & 5,1 \\
\hline
\end{tabular}

T - testemunha; A - açúcar; PC - polpa cítrica; MM - milho moído; $1 \%$ do nitrogênio total; CV-coeficiente de variação. Médias seguidas de letras distintas, na mesma linha, diferem $(P<0,05)$ pelo teste Tukey.

$C$ - control; S - sugar; CP - citric pulp; GC - ground corn; ${ }^{1} \mathrm{mgeClH} / 100 \mathrm{~g} \mathrm{DM} ; \mathrm{CV}$ - coefficient of variation.

Means followed by different letters, in the same row, are different $\left(P_{<}\right.$.05) by Tukey test. 
para o processo de fermentação lática, ao contrário dos CHOS da PC, resultando na elevação do teor de N$\mathrm{NH}_{3}$ e alto $\mathrm{pH}$ para a silagem com MM. Isso é coerente com as citações de LAVEZZO e ANDRADE (1994) e VILELA (1998) de que o amido do milho não é fermentado pelas bactérias láticas.

O maior teor de $\mathrm{PB}(\mathrm{P}<0,05)$ foi encontrado para a silagem com MM, seguida da silagem com PC, o que, em parte, é consequência da ocorrência, no silo, de alta degradação protéica.

Em comparação com silagens de outras espécies, o teor protéico das silagens de subprodutos da pupunha foi de 2,2 a 4,9 unidades percentuais superior à média de 6,3\% obtida por ALMEIDA FILHO et al. (1999) para silagens de milho, e 6,3 a $7,9 \%$ obtidos por CÂNDIDO et al. (1999) para silagens de sorgo. Comparando-se os teores de proteína das silagens de capim-elefante, levantados na literatura por LAVEZZO (1993), notam-se valores inferiores e superiores aos obtidos com as silagens de subproduto da pupunha.

Os teores de fibra das silagens sem aditivo ou com 2,5\% de A foram bastante altos mas decresceram $(\mathrm{P}<0,05)$ sensivelmente com o uso de $\mathrm{PC}$ e reduziram $(\mathrm{P}<0,05)$ ainda mais com o uso de MM. Este fato está associado com o menor teor de fibra dos aditivos, ocorrendo o efeito de diluição, também observado por ANDRADE e LAVEZZO (1998a).

$A$ adição de $\mathrm{A}$ e $\mathrm{MM}$ elevaram $(\mathrm{P}<0,05)$ os teores de extrato etéreo das silagens, enquanto a presença de PC não alterou este parâmetro. O coeficiente de variação para este nutriente foi alto $(22,5 \%)$. De acordo com ANDRADE e LAVEZZO (1998a) os ácidos orgânicos produzidos nas silagens elevam o teor de EE das mesmas.

O menor $(\mathrm{P}<0,05)$ teor de matéria mineral encontrado na silagem confeccionada com $10 \%$ de MM, pode também estar associado com fator diluição. A matéria mineral do MM é de 1,6\% (NRC, 1996), enquanto na PC pode variar de 3,0 a $17,0 \%$ (CARVALHO, 1994) e no melaço de cana de 9,4 a $14,2 \%$ (BURGI, 1994). De modo geral os valores são semelhantes aos obtidos por ANDRADE e LAVEZZO (1998a) para silagens de capim-elefante produzidas com diversos aditivos.

Quanto aos constituintes da parede celular (FDN, FDA, celulose e lignina), nota-se redução dos seus teores com a adição de PC ou MM, conseqüência do menor teor desses componentes estruturais nos aditivos utilizados, em relação aos subprodutos da pupunha, havendo um efeito de diluição. Resultados semelhantes foram obtidos por COAN et al. (1998) com ensilagem de aveia, BERGAMASCHINE et al. (1998) com ensilagem de capim-Tanzânia e RUGGIERI (1996) com ensilagem de alfafa; todos utilizando MM como aditivo. A menor redução na FDN encontrada na silagem com MM, em comparação com PC, pode estar relacionada com a presença de amido interferindo na análise da FDN, já que não foi utilizado amilase durante a mesma.

Os teores de FDN obtidos para as silagens sem aditivo ou com A, foram semelhantes aos obtidos por ANDRADE et al. (1998), trabalhando com silagem de capim-elefante, e tanto a FDN como a FDA foram muito próximas àquelas da silagem de capim-Tanzânia obtidas por BERGAMASCHINE et al. (1998).

As silagens confeccionadas com PC ou MM apresentaram teores de FDN e FDA ao redor de 7,0 e 10,0 unidades percentuais, respectivamente, mais elevados que as silagens de híbridos de milho estudadas por ALMEIDA FILHO et al. (1999). Isto na verdade, reflete a elevada idade de corte da planta, necessária para a produção do palmito, reduzindo consequentemente, o valor alimentar do subproduto.

As silagens feitas sem aditivo ou com A apresentavam cor amarela escura e cheiro fraco, quase inodoro, enquanto as silagens com MM e PC, apresentaram cor amarela mais clara e cheiro forte. Essas últimas, apresentaram maiores teores de matéria seca e um melhor padrão de fermentação, traduzido pelos menores teores de $\mathrm{N}-\mathrm{NH}_{3}$ e menores valores de $\mathrm{pH}$, resultando em maior $(\mathrm{P}<0,05)$ consumo de matéria seca (Tabela 3).

$A$ adição de $\mathrm{A}$, embora tenha resultado em um padrão de fermentação próximo ao das silagens com PC e MM, não elevou o teor de matéria seca da mesma, possivelmente resultando em baixo consumo semelhante ao da silagem sem aditivo (T). De acordo com McDONALD et al. (1988) existe uma correlação negativa entre ingestão de matéria seca e concentração de $\mathrm{N}-\mathrm{NH}_{3}$ e, entre esta e o teor de matéria seca da massa a ser ensilada.

WILKINS et al. (1971) afirmaram que o teor de matéria seca pode explicar somente $15,8 \%$ nas variações de consumo entre silagens. Desta forma, pode-se especular que outros fatores contribuíram para as diferenças observadas no consumo de matéria seca (Tabela 3). PORDOMINGO et al. (1991) observaram um efeito estimulante de pequena quantidade $(0,2 \% \mathrm{PV})$ de milho sobre a ingestão de forragens.

O consumo das silagens com PC ou MM foi acima de $80 \mathrm{~g} / \mathrm{Kg} \mathrm{PV}^{0,75}$, que é o preconizado por 
Rev. bras. zootec.

CRAMPTON et al. (1960) para volumoso de alta palatabilidade. Com silagem de aveia, confeccionada com 10\% de MM, LOPEZ e MÜHLBACH (1994) trabalhando com ovinos, encontraram consumo de $56,4 \mathrm{~g} / \mathrm{kg} \mathrm{PV}^{0,75}, 13,0$ unidades a mais que o obtido para silagem sem aditivo.

O consumo de matéria seca da silagem sem aditivo ou com A permitiu ingestão de 17,0 MJ EM/ dia, enquanto o consumo de matéria seca das silagens com PC ou MM possibilitou a ingestão de 39,5 MJ
EM/dia para animais de $180 \mathrm{~kg}$ de peso vivo, com exigência de energia metabolizável de mantença 27,3 MJ/dia, conforme AFRC (1993).

Quanto ao coeficiente de digestibilidade da matéria seca das silagens (Quadro 3), observa-se que apenas a PC e o MM elevaram $(\mathrm{P}<0,05)$ o valor desse parâmetro, em relação a silagem sem aditivo. Entretanto, ANDRADE e LAVEZZO (1998b) observaram um efeito cúbico na digestibilidade da silagem de capim-elefante, com níveis $0 ; 8,0 ; 16,0$ e $24,0 \%$ de aditivo (farelo de trigo

Tabela 3 - Consumo, coeficiente de digestibilidade aparente dos nutrientes e valores de NDT das silagens de subprodutos da pupunha de acordo com os tratamentos

Table 3 - Intake, apparent digestibility coefficient of nutrients and TDN values of palm bybproduct silages, according to the treatments

\begin{tabular}{|c|c|c|c|c|c|}
\hline \multirow[t]{3}{*}{$\begin{array}{l}\text { Parâmetros } \\
\text { Parameter }\end{array}$} & \multicolumn{4}{|c|}{$\begin{array}{c}\text { Tratamentos } \\
\text { Treatments }\end{array}$} & \multirow{3}{*}{$\mathrm{CV} \%$} \\
\hline & $\mathrm{T}$ & $\mathrm{A}(2,5 \%)$ & $\mathrm{PC}(10 \%)$ & $\mathrm{MM}(10 \%)$ & \\
\hline & $C$ & $S$ & $C P$ & $G C$ & \\
\hline \multicolumn{6}{|l|}{$\begin{array}{l}\text { Consumo } \\
\text { Intake }\end{array}$} \\
\hline $\begin{array}{l}\mathrm{gMS} / \mathrm{kg} \mathrm{PV} \mathrm{PV}^{0,75} \\
\mathrm{gDM} / \mathrm{kgLW}^{0.75}\end{array}$ & $44,5^{\mathrm{b}}$ & $44,9^{\mathrm{b}}$ & $87,0^{\mathrm{a}}$ & $84,1^{\mathrm{a}}$ & 9,2 \\
\hline $\begin{array}{l}\mathrm{kgMS} / 100 \mathrm{kgPV} \\
\mathrm{kgDM} / 100 \mathrm{~kg} L W\end{array}$ & $1,13^{\mathrm{b}}$ & $1,11^{\mathrm{b}}$ & $2,14^{\mathrm{a}}$ & $2,06^{\mathrm{a}}$ & 9,3 \\
\hline \multicolumn{6}{|c|}{$\begin{array}{l}\text { Digestibilidade }(\%) \\
\text { Digestibility }\end{array}$} \\
\hline $\begin{array}{l}\mathrm{MS} \\
D M\end{array}$ & $53,9^{\mathrm{b}}$ & $50,5^{\mathrm{b}}$ & $64,7^{\mathrm{a}}$ & $65,4^{\mathrm{a}}$ & 14,5 \\
\hline $\begin{array}{l}\mathrm{PB} \\
C P\end{array}$ & $60,2^{\mathrm{b}}$ & $58,5^{\mathrm{b}}$ & $63,0^{\mathrm{b}}$ & $71,0 \mathrm{a}$ & 5,9 \\
\hline $\begin{array}{l}\mathrm{FB} \\
\mathrm{CF}\end{array}$ & $58,0 \mathrm{a}$ & $51,4^{\mathrm{ab}}$ & $54,0^{\mathrm{ab}}$ & $44,5^{\mathrm{b}}$ & 9,4 \\
\hline $\mathrm{EE}$ & $57,4^{\mathrm{b}}$ & $79,5 \mathrm{a}$ & $73,2^{\mathrm{ab}}$ & $86,0^{\mathrm{a}}$ & 11,9 \\
\hline $\begin{array}{l}\mathrm{ENN} \\
\tilde{N} N E\end{array}$ & $47,5^{\mathrm{b}}$ & $51,1^{\mathrm{b}}$ & $78,2^{\mathrm{a}}$ & $80,0^{\mathrm{a}}$ & 4,3 \\
\hline $\begin{array}{l}\text { FDN } \\
N D F\end{array}$ & $50,0^{\mathrm{ab}}$ & $44,1^{b}$ & $52,7^{\mathrm{a}}$ & $55,3^{\mathrm{a}}$ & 6,5 \\
\hline $\begin{array}{l}\text { FDA } \\
A D F\end{array}$ & $48,6^{\mathrm{ab}}$ & $45,0^{\mathrm{b}}$ & $56,^{\mathrm{a}}$ & $45,2^{\mathrm{b}}$ & 9,2 \\
\hline $\begin{array}{l}\text { Celulose } \\
\text { Cellulose }\end{array}$ & $59,3^{\mathrm{a}}$ & $60,0^{\mathrm{a}}$ & $63,3^{\mathrm{a}}$ & $54,4^{\mathrm{a}}$ & 7,8 \\
\hline $\begin{array}{l}\text { Hemicelulose } \\
\text { Hemicellulose }\end{array}$ & $48,0^{\mathrm{b}}$ & $30,0^{c}$ & $41,8^{a}$ & $75,7^{\mathrm{a}}$ & 10,3 \\
\hline $\begin{array}{l}\mathrm{CHO} \\
\text { Lignina }\end{array}$ & $\begin{array}{l}54,0^{\mathrm{b}} \\
32,0^{\mathrm{b}}\end{array}$ & $\begin{array}{l}50,0^{\mathrm{b}} \\
33,4^{\mathrm{ab}}\end{array}$ & $\begin{array}{l}65,8^{\mathrm{a}} \\
47,3^{\mathrm{a}}\end{array}$ & $\begin{array}{l}65,0^{\mathrm{a}} \\
36,7^{\mathrm{ab}}\end{array}$ & $\begin{array}{r}5,2 \\
18,0\end{array}$ \\
\hline $\begin{array}{l}\text { Lignin } \\
\text { NDT }^{1} \\
T_{D N}{ }^{1}\end{array}$ & $52,2^{\mathrm{b}}$ & $51,3^{\mathrm{b}}$ & $63,3^{\mathrm{a}}$ & $66,4^{\mathrm{a}}$ & 4,6 \\
\hline $\begin{array}{l}\mathrm{NDT}^{2} \\
T D N^{2}\end{array}$ & $52,0^{\mathrm{b}}$ & $53,8^{\mathrm{b}}$ & $64,4^{\mathrm{a}}$ & $66,4^{\mathrm{a}}$ & 4,9 \\
\hline
\end{tabular}

T - testemunha; A - açúcar; PC - polpa cítrica; MM - milho moído; CV - coeficiente de variação. Médias seguidas de letras distintas, na mesma linha, diferem $(P<0,05)$ pelo teste Tukey; ${ }^{1}$ SNIFFEN (1992); $2 \mathrm{NDT}=\mathrm{PD}+\mathrm{FD}+\mathrm{EDD} \times 2,25+$ EÑND.

$C$ - control; $S$ - sugar; $C P$ - citric polp; GC - ground corn; $C V$ - coefficient of variation.

Means followed by different letters, in the same row, are different $(P<.05)$ by Tukey test; ${ }^{1}$ SNIFFEN $(1992) ;{ }^{2}$ TDN $=D P$ $+D F+D E E \times 2.25+D \tilde{N} N E$. 
ou rolão de milho), quando oferecida para ovinos. Este fato foi associado com uma queda na digestibilidade dos componentes da parede celular, em face de menor atividade de bactérias celulolíticas. Trabalhando com aveia, LOPEZ E MÜHLBACH (1994) não obtiveram melhora na digestibilidade da matéria seca, ao adicionarem $10 \%$ de $\mathrm{MM}$, porém a digestibilidade da fibra bruta decresceu em 12,2 unidades percentuais. No presente trabalho os dados mostraram que a adição de $10 \%$ de MM ao subproduto da pupunha, aumentou a digestibilidade da matéria seca mas houve uma redução de 13,5 unidades percentuais na digestibilidade da $\mathrm{FB}$, em relação à silagem sem aditivo.

A digestibilidade da proteína bruta foi maior $(\mathrm{P}<0,05)$ na silagem feita com MM. A silagem com $\mathrm{PC}$, embora apresentasse teor protéico superior $(\mathrm{P}<0,05)$ às silagens sem aditivo ou com $\mathrm{A}$, não apresentou diferenças na digestibilidade da proteína. A coloração escura da PC utilizada caracteriza superaquecimento ocorrido na industrialização. $\mathrm{O}$ aquecimento reduz a solubilidade das proteínas e consequentemente reduz também a degradabilidade ruminal. Os coeficientes de digestibilidade aparente da proteína de todas as silagens do presente trabalho, foram superiores aos observados por PEREIRA et al. (1993) para silagens de milho e de sorgo, cuja variação foi de 46,6 a $54,3 \%$.

A maior digestibilidade $(\mathrm{P}<0,05)$ do extrato etéreo e CHOT nas silagens com aditivo, é conseqüência dos maiores teores de EE e menores teores de $\mathrm{CHO}$ estruturais nessas silagens (ARAÚJO et al., 1998).

O coeficiente de digestibilidade da celulose não foi afetado $(\mathrm{P}>0,05)$ pelos aditivos. A média de $59,0 \%$ é inferior aos $67,0 \%$ para silagem de capimelefante encontrado por ANDRADE e LAVEZZO (1998b), que também observaram queda nesse parâmetro com a presença de aditivo.

Os valores energéticos das silagens foram estimados por intermédio dos nutrientes digestíveis totais (NDT), calculado conforme SNIFFEN (1992) e também pela fórmula tradicional: NDT $=\mathrm{PD}+\mathrm{FD}$ + EED x 2,25 + EÑND.

A PC e o MM elevaram $(\mathrm{P}<0,05)$ o teor de NDT das silagens, de 51,8 para $64,8 \%$ em média; enquanto a adição de A não afetou $(\mathrm{P}<0,05)$ o valor do NDT. Resultados semelhantes foram obtidos por LÓPEZ e MÜHLBACK (1994) ao adicionarem $10 \%$ de MM na ensilagem de aveia e ANDRADE e LAVEZZO (1998b) para silagem de capim-elefante produzida com $8 \%$ de farelo de trigo ou rolão de milho. Com variedades de sorgo colhidos em três estádios de maturidade, ANDRADE e CARVALHO (1992) encontraram teor de NDT médio de 62,0\%. CARVALHO (1994) revisando a literatura cita valores de NDT de 56,2; 62,2 e $60,8 \%$ para silagens de capim-elefante, de milho e de capim-elefante mais $20 \%$ de PC, respectivamente, ressaltando que a silagem de capim elefante, produzida com $20 \%$ de PC, foi de qualidade e custo semelhante à silagem de milho.

\section{Conclusões}

A ensilagem do subproduto da pupunha, constituído de folhas, bainhas e parte dos caules, pura ou com 2,5\% de açúcar, resultou em um volumoso de baixa qualidade, entretanto, a adição de $10 \%$ de polpa cítrica ou milho moído proporcionou silagens de qualidade média e valor nutritivo semelhante à maioria das silagens de forrageiras convencionais.

\section{Referências Bibliográficas}

AGRICULTURAL AND FOOD RESEARCH COUNCIL AFRC. 1993. Energy and protein requirements of ruminants. Wallingford: CAB International. p.159.

ALMEIDA FILHO, S.L., FONSECA, D.M., GARCIA, R. et al. 1999. Características agronômicas de cultivares de milho (Zea mays L.) e qualidade dos componentes e das silagens. Rev. bras. zootec., 28(1):7-13.

ALVES JR., J., LOPES, A.S., ALVES, R.R. et al. Influência de diferentes níveis de irrigação na cultura da pupunha na produção de resíduos, objetivando seu uso na alimentação animal. In: CONGRESSO DE INICIAÇÃO CIENTÍFICA, 11, 1999, Botucatu. Anais... Botucatu: UNESP/FCA, 1999. p.193.

ANDRADE, J.B., CARVALHO, D.D. 1992. Estádio de maturação na produção e qualidade da silagem de sorgo II. Digestibilidade e consumo da silagem. Bol. Ind. Anim. 49(2):101-106.

ANDRADE, F.F. Composição mineral e determinação de proteína bruta em folhas de pupunha (Bactris gasipae H. B. K.). Jaboticabal: UNESP, 1997. 49p. Monografia (Trabalho de Graduação) - Faculdade de Ciências Agrárias e Veterinária, 1997.

ANDRADE, J.B., FERRARI JR., E., LEITE, V.B.O. et al. 1998 Prensagem da forragem e adição de rolão de milho na ensilagem do capim-elefante. 1 - Composição do material a ser ensilado. Bol. Ind. Anim., 55(1):71-79.

ANDRADE, J.B., LAVEZZO, W. 1998a. Aditivos na ensilagem do capim-elefante. I. Composição bromatológica das forragens e respectivas silagens. Pesq. Agropec. Bras., 33(11):1859-1872.

ANDRADE, J.B., LAVEZZO, W. 1998b. Aditivos na ensilagem do capim-elefante. III. Valor nutritivo e consumo voluntário e digestibilidade aparente em ovinos. Pesq. Agropec. Bras., 33(12):2015-2023.

ARAUJO, G.G.L., COELHO DA SILVA, J.F., VALADARES FILHO, S.C. et al. 1998. Consumo e digestibilidade total dos nutrientes de dietas contendo diferentes níveis de volumosos em bezerros. R. Bras. Zootec., 27(2):345-354. 
BERGAMASCHINE, A.F., ISEPON, O.J., GUATURA, A.S. et al. Efeitos da adição de resíduo de milho e da cultura enzimobacteriana sobre qualidade da silagem do capim Tanzânia. In: REUNIÃO ANUAL DA SOCIEDADE BRASILEIRA DE ZOOTECNIA, 35, 1998, Botucatu. Anais... Botucatu: SBZ, 1998. (CD-ROOM - FOR030)

BOIN, C. Nutrição e manejo da alimentação de bovinos de corte em confinamento. In: SEMINÁRIO SOBRE TECNOLOGIA DA PRODUÇÃO DE RAÇÕES, 3, 1992, Campinas. Anais ... Campinas: CBNA, 1992. p.27-61.

BOTREL, M.A., XAVIER, D.F. 1998. Cultivares de capim elefante para o Estado de Minas Gerais. Inf. Agropec., 19(192):14-16.

BURGI, R. Cana-de-açúcar. In: SIMPÓSIO SOBRE NUTRIÇÃO DE BOVINOS (UTILIZAÇÃO DE RESÍDUOS CULTURAIS E DE BENEFICIAMENTO NA ALIMENTAÇÃO DE BOVINOS), 6, 1994, Piracicaba. Anais... Piracicaba: FEALQ, 1994. p.153-169.

CANDIDO, M.J.D., OBEID, J.A., PEREIRA, O.G. et al. Avaliação da produção e do valor nutritivo das silagens de cinco híbridos de sorgo. In: REUNIÃO ANUAL DA SOCIEDADE BRASILEIRA DE ZOOTECNIA, 36, 1999. Porto Alegre. Anais...Porto Alegre: SBZ, 1999. (CD-ROOM-FOR056).

CARVALHO, M.P. Citros. In: SIMPÓSIO SOBRE NUTRIÇÃO DE BOVINOS (UTILIZAÇÃO DE RESÍDUOS CULTURAIS E DE BENEFICIAMENTO NA ALIMENTAÇÃO DE BOVINOS), 6, 1994, Piracicaba. Anais ... Piracicaba: FEALQ, 1994. p.171-214.

COAN, R.M., REIS, R.A., RODRIGUES, L.R.A. et al. Fubá de milho como aditivo para ensilagem de aveia. In: REUNIÃO ANUAL DA SOCIEDADE BRASILEIRA DEZOOTECNIA, 35, 1998, Botucatu. Anais... Botucatu: SBZ, 1998. (CDROOM- FOR125)

CRAMPTON, E.W., DONEFER, E., LLOYD, L.E. 1960. A nutritive value indix for forages. J. Anim. Sci., 19(4): 538-544.

FARIA, V.P., TOSI, H., GODOY, C.R.M. 1972. Polpa de laranja fresca e seca como aditivos para a ensilagem do capim elefante napier. O Solo, 64(1): 41-47.

HENRIQUE, W., COUTINHO FILHO, J.L.V., JUSTO, C.L. et al. Avaliação da produtividade, porcentagem de grãos na massa, qualidade da silagem e produção de grãos de onze híbridos de milho. In: REUNIÃO ANUAL DA SOCIEDADE BRASILEIRA DE ZOOTECNIA, 34, 1997, Juiz de Fora. Anais... Juiz de Fora: SBZ, 1997. p.173-175.

JOHNSON, R.N., BALINANI, T.L., JOHNSON, L.L. et al. 1966. Corn plant maturity. II. Effect on "in vitro" cellulose digestibility and soluble carbohydrate content. J. Anim. Sci., 25:617-623.

LAVEZZO, W. Ensilagem do capim-elefante. In: SIMPÓSIO SOBRE MANEJO DA PASTAGEM, 10, 1993, Piracicaba. Anais...Piracicaba: FEALQ, 1993. p.169-275.

LAVEZZO, W., ANDRADE, J.B. Conservação de forragens: feno e silagem. In: SIMPÓSIO BRASILEIRO DE FORRAGEIRAS E PASTAGENS, 1994, Campinas. Anais ... Campinas: CNBA, 1994. p. 105-166.

LOPES, S.E., MÜHLBACH, P.R.F. 1994. Efeito de diferentes tratamentos no valor nutritivo da aveia branca (Avena sativa L.) conservada nas formas de silagem ou feno. R. Soc. Bras. Zootec., 23(4):518-526.

MALAVOLTA, M., VITTI, G.C., OLIVEIRA, S.A. 1997. Avaliação do estado nutricional das plantas: princípios e aplicações. 2.ed. Piracicaba: POTAFOS. 319p.

MAZZA, J.A. Estabelecimento e manejo da cultura da cana-deaçúcar. In: SIMPÓSIO SOBRE NUTRIÇÃO DE BOVINOS, 5, 1993, Piracicaba. Anais ... Piracicaba: FEALQ, 1993. p.37-76.

McDONALD, P., EDWARDS, R.A. GREENHALGH, J.F.D. 1988. Animal nutrition. New York: Longman Scientific Technical. 525p.
MEDEIROS, L.M. Subproduto da extração do palmito pupunha (Bactris gasipaes) na alimentação de bovinos confinados. In: CONGRESSO DE INICIAÇÃO CIENTÍFICA, 11, 1999, Botucatu. Anais ... Botucatu: UNESP/FCA, p.264. 1999.

NATIONAL RESEARCH COUNCIL - NRC. 1996. Nutrients requirements of beef cattle. 7. Revised Ed., Washington, D.C.: National Academy Press. 242p.

PEREIRA, O.G., OBEID, J.A., GOMIDE, J.A. et al. 1993. Produtividade de uma variedade de milho (Zea mays L.) e de três variedades de sorgo (Sorghum bicolor (L.) Moench) e o valor nutritivo de suas silagens. R. Soc. Bras. Zootec., 22(1):31-38.

PLAYNE, M.J., McDONADL, P. The buffering constituints of herbage and of silage. 1966. J. Sci. Food Agric., 17(2):264-268.

PORDOMINGO, A.J., WALLACE, J.D., FREEMAN, A.S. et al. 1991. Suplemental corn grain for steers grazing native rangeland during summer. J. Anim. Sci., 69:1678-1687.

RUGGIERI, A.C. Efeito do emurchecimento e da adição de fubá de milho na qualidade e valor nutritivo da silagem de alfafa. Botucatu, 1996. 41p. Dissertação (Mestrado em Zootecnia) Faculdade de Medicina Veterinária e Zootecnia (Universidade Estadual Paulista), 1996.

SILVA, D.J. 1981. Análise de alimentos: métodos químicos e biológicos. Viçosa: UFV. 166p.

SNIFFEN, C.J., O'CONNOR, J.D., VAN SOEST, P.J. et al. 1992. A net carbohydrate and protein system for evaluating cattle diets. II. Carbohydrate and protein availability. J. Anim. Sci., 70:3551-3561.

TONET, R.M., FERREIRA, L.G.S., OROBONI, J.L.M. 1999a. A cultura da pupunha (Bactris gasipaes). Campinas: CATI. 44p. (Boletim técnico, 237)

TONET, R.M., FERREIRA, L.G.S., OROBONI, J.L.M. 1999b. Levantamento e situação da cultura da pupunha no Estado de São Paulo. Campinas: CATI. 9p. (Documento técnico, 111)

TOSI, H. Ensilagem de gramíneas tropicais sob diferentes tratamentos. Botucatu, 1973. 107p. Tese (Doutorado em Ciências Biológicas) - Faculdade de Ciências Médicas e Biológicas de Botucatu/Universidade Estadual Paulista, 1973.

TOSI, H., FARIA, V.P., GUTIERRZ, L.E. et al. 1983. Avaliação do capim elefante, cultivar TAIWAN A-148, como planta para ensilagem. Pesq. Agropec. Bras., 18(3):295-299.

TOSI, H., RODRIGUES, L.R.A., JOBIM, C.C. et al. 1996. Ensilagem do capim elefante cv. Mott sob diferentes tratamentos. R. Soc. Bras. Zootec., 24(6):909-916.

VAN ONSELEN, V.J., LOPEZ, J. 1988. Efeito da adição de fontes de carboidratos e de um produto enzimático comercial na composição químico-bromatológica da silagem de capim elefante. R. Soc. Bras. Zootec., 17(5):421-427.

VILELA, D. 1984. Aditivos na ensilagem. Juiz de Fora: EMBRAPA/ CNPGL. 15p. (Circular técnico, 21)

VILELA, D. Aditivos para silagem de plantas de clima tropical. In: SIMPÓSIO SOBRE ADITIVOS NA PRODUÇÃO DE RUMINANTES E NÃO RUMINANTES, REUNIÃO DA SOCIEDADE BRASILEIRA DE ZOOTECNIA, 35, 1998, Botucatu. Anais ... Botucatu: SBZ, 1998. p.73-108.

WILKINS, R.J.,HUTCHINSON, K.J., WILSON, R.F. etal. 1971. The voluntary intake of silage for sheep. I. Interrelationship between silage composition and intake. J. Agric. Sci., 77(3):531-537.

Recebido em: 29/11/00 Aceito em: 17/04/01 